\title{
STUDY THE STABLE STRUCTURES OF ScGe6 BY GA-DFT AND THE CO ADSORPTION ON ScGe6 ${ }^{-}$CLUSTER
}

\author{
NGUYEN MINH THAO ${ }^{1,2}$, BUI THO THANH ${ }^{1}$, NGUYEN THI LAN HUONG ${ }^{3}$ \\ ${ }^{1}$ Faculty of Chemistry, University of Science, VNU-HCM, \\ ${ }^{2}$ Dong Thap University, \\ ${ }^{3}$ Ho Chi Minh University of Natural Resources and Environment \\ nmthao@dthu.edu.vn,btthanh@hcmus.edu.vn,ntlhuong@hcmunre.edu.vn
}

\begin{abstract}
The structures of $\mathrm{ScGe}_{6}$ and $\mathrm{ScGe}_{6}{ }^{-}$clusters were investigated by a combination of genetic algorithm with quantum chemical calculations (GA-DFT and DLPNO-CCSD(T)). Results show that the two most stable isomers of the $\mathrm{ScGe}_{6}$ cluster have a pentagonal bipyramid structure with a $\mathrm{Sc}$ atom at the vertex and a Ge atom capping the face of tetragonal bipyramid with a Sc atom at the vertex with $\mathrm{C}_{s}$ symmetry. The pentagonal bipyramid with the scandium atom at the vertex with $\mathrm{C}_{5 v}$ symmetry is the most stable $\mathrm{ScGe}_{6}{ }^{-}$cluster. The $\mathrm{CO}$ adsorption on the most stable isomer of the anionic cluster was studied by $\mathrm{PBE}$ functional. The isomer A1 of $\mathrm{ScGe}_{6}{ }^{-}$cluster can adsorb $\mathrm{CO}$ molecule as well. The most stable structure has $\mathrm{CO}$ along with the Sc-Ge bond. In two adsorption models at the Sc atom along the main axis, the Sc$\mathrm{CO}$ adsorption model is more favorable than the Sc-OC model.
\end{abstract}

Keywords: $\mathrm{ScGe}_{6}{ }^{0 /-}$ cluster, genetic algorithm, DFT, DLPNO-CCSD(T), CO adsorption

\section{INTRODUCTION}

Germanium clusters have been interested in widely application abilities in electronic, adsorption, catalyst, pharmacy field [1-4]. Clearly, germanium was used to produce LED, solar cell, lithium-ion battery with faster charge-discharge ability, stably through a large number of the cycle [3]. In addition, germanium can be used in pharmacy because of its non-toxic and high bio-compatibility [2]. The optic property, electronic property, stability of materials depends on their size $[4,5]$. The small cluster can be a structural unit to build nanomaterials, bulky materials. Therefore, it is necessary to study the structure of small clusters to design new material which has high applications. The structures of germanium, scandium were studied as $\mathrm{Ge}_{n}$ (n=1-20) [6], $\mathrm{Ge}_{n}(n=2-6)$ [7, 8], $\mathrm{Ge}_{n}(n=2-13)$ [9], $\mathrm{Ge}_{n}(n=2-25)$ [10], $\mathrm{Ge}_{n}(n=3-7)$ [8], $\mathrm{Ge}_{27}^{-}$[11], $\mathrm{Ge}_{3-4}$ [12], $\mathrm{Ge}_{n}{ }^{0 /+}(n=8,9,10,11,12,13,15,16)$ [13], $\mathrm{Sc}_{2-3}$ [14], $\mathrm{Sc}_{n}{ }^{+}(n=2-13)$ [15], $\mathrm{Sc}_{n}{ }^{-}(n=2-13)$ [16], $\mathrm{Sc}_{n}$ and $\mathrm{Sc}_{n} \mathrm{O}(n=2-13)$ [17], $\mathrm{ScGe}_{n}{ }^{-}(n=6-20)[18,19]$. These results indicated that the stability and property of transition metal-doped germanium are higher than pure germanium clusters [5, 20-23]. Because the $3 d$ orbitals have near degeneration in energy, transition metal-doped germanium clusters can build many structures that have the same stability $[6,9,18,24]$.

In modern society, environmental pollutions have been interested. $\mathrm{CO}$ which is formed in burning fuels is one of the toxic pollutants. Many studies have been performed to find out the ways to remove CO. Scandium, germanium clusters are the good materials to adsorb CO. [16, 25-27] Three isomers of $\mathrm{ScGe}_{6}$ cluster include isomer A, isomer B, isomer C [18]. The structure of isomer A is a pentagonal bipyramid with the scandium atom at one of the vertices. The structure of isomer B is two perpendicular rhomboid units that connect via a scandium atom. Isomer $\mathrm{C}$ 's structure is also a pentagonal bipyramid with a scandium atom in its base. [18] The structure of the $\mathrm{ScGe}_{6}$ cluster is still not reported.

To search for the global minimum structure, the genetic algorithm combines quantum chemistry calculation is one of useful methods. GA-DFT can find the global structure with high exact [28]. The density functional theory can optimize the structure cluster cheap and fast. The coupled-cluster CCSD(T) is the gold standard in quantum chemistry calculation. The $\operatorname{CCSD}(\mathrm{T})$ calculations require a strong computer with large memory and a long time to calculate. So, the $\operatorname{CCSD}(\mathrm{T})$ can be used for small size clusters. The DLPNO-CCSD(T) method in ORCA code can be used for larger size clusters than in $\operatorname{CCSD}(\mathrm{T})$ because of approximations. The DLPNO-CCSD(T) calculation can calculate $99 \%$ of the correlation energy of the CCSD(T) calculation. [29-31] 
In this study, we use GA-DFT to search the stable structures of the $\mathrm{ScGe}_{6}$ cluster. The anionic clusters' structures are optimized from neutral clusters' structures. Besides, we also build some local structures which were obtained from different references to compare [18]. Many stable structures of $\mathrm{ScGe}_{6}{ }^{0 /-}$ clusters have been reported. The $\mathrm{CO}$ adsorption by anionic cluster $\mathrm{ScGe}_{6}{ }^{-}$is studied on the most stable isomer to find the stable structures of $\mathrm{CO}$ adsorption.

\section{CALCULATION METHODS}

The structures of neutral cluster $\mathrm{ScGe}_{6}$ were investigated by GA-DFT combined with the genetic algorithm and density functional theory [28-32]. The parameters of genetic algorithm were set up as 20 randomly initial structures, 15 structures in the next generations include $40 \%$ structures were kept from the previous generation, 20\% mutation structures, 20\% crossing structures, and 20\% new random structures. A maximum generation of 10 was chosen. The stop condition of the process is 5 generations which have the energy error is not passed $0.01 \mathrm{eV}$ or maximum generation have been done. GA process was performed by USPEX 10.3 code [33-35]. The energies of these processes were calculated by the pwscf code of the Quantum Espresso 6.0 package [36]. Besides, some local minimum structures were built from other references.

All obtained structures were reoptimized by PBE functional [37]. To save calculation time, the geometrical structure was optimized by a small basis set def2-SVP. Then, re-optimization was done by larger basis set def2-TZVPP. The relative energy and frequency values of optimized structures were obtained. The relative energies were calculated as the different between the energy of every cluster and the minimum energy of energy values of isomers. All position frequencies of clusters indicate that this structure is at the minimize position on the potential surface. The get better correlation energy, the DLPNO-CCSD(T) method [38, 39] was chosen to perform the single-point calculation for optimized geometry of cluster. The aug-cc-pVTZ basis set was used in DLPNO-CCSD(T) calculations. The DFT and DLPNO-CCSD(T) calculations were performed by ORCA 4.2.1 code [40].

The CO adsorption processes were studied by PBE functional. The initial structures of adsorption were created by putting $\mathrm{CO}$ up many different positions around the surface of the $\mathrm{ScGe}_{6}{ }^{-}$cluster. First, the optimization was performed not to constrain point group symmetry. Then, the near symmetry was chosen. The def2-TZVPP basis set is used for all elements. The frequency values of adsorption structures were also calculated to confirm the obtained structure at the minimize position on the potential surface.

\section{RESULTS AND DISCUSSION}

\subsection{Structure, relative stability of $\mathrm{ScGe}_{6}$ clusters}

The geometrical structures, symmetry point group, relative energies (RE) of 10 isomers were presented in Figure 1 and Table 1. These isomers' structures of the $\mathrm{ScGe}_{6}$ cluster are still not searched in the other references. As following results of relative energies by DLPNO-CCSD(T), the N1 isomer whose structure has $\mathrm{C}_{s}$ symmetry is the most stable isomer. The other isomers as $\mathrm{N} 2, \mathrm{~N} 3, \mathrm{~N} 4, \mathrm{~N} 5, \mathrm{~N} 6, \mathrm{~N} 7, \mathrm{~N} 8, \mathrm{~N} 9, \mathrm{~N} 10$ is less stable than $\mathrm{N} 1$ by $0.05,0.16,0.20,0.24,0.55,0.66,0.68,0.78,1.21 \mathrm{eV} \mathrm{eV}$. As initial prediction by $3 \mathrm{~d}$ orbital, many structures have the equivalent energy. The $\mathrm{N} 2$ isomer is near generated about energy with $\mathrm{N} 1$ isomer by $0.05 \mathrm{eV}$ of relative energy. Three isomers $\mathrm{N} 3, \mathrm{~N} 4, \mathrm{~N} 5$ have equivalent stability. The relative energies of three isomers are respectively $0.16,0.20,0.24 \mathrm{eV}$ from the DLPNO-CCSD(T) calculations. Four isomers of N6, N7, N8, N9 are small differences in energy.

The order of stability of N1, N2, N3, N4, N5 isomers by PBE functional are different from DLPNO$\operatorname{CCSD}(\mathrm{T})$ calculation. The values of relative energies of these five clusters at PBE functional are N3 (0.00 $\mathrm{eV})<\mathrm{N} 1(0.02 \mathrm{eV})<\mathrm{N} 2(0.07 \mathrm{eV})<\mathrm{N} 5(0.23 \mathrm{eV})<\mathrm{N} 4(0.28 \mathrm{eV})$. This difference can be explained by the different calculation abilities of correlation energy by different calculation methods [41]. The DLPNO$\operatorname{CCSD}(\mathrm{T})$ can calculate about $99 \%$ of correlation energy than the gold standard $\operatorname{CCSD}(\mathrm{T})$ [30, 31]. Therefore, correlation energy plays important role to compare the stability of isomers, especially with transition metal-doped clusters because of energy degeneration. 

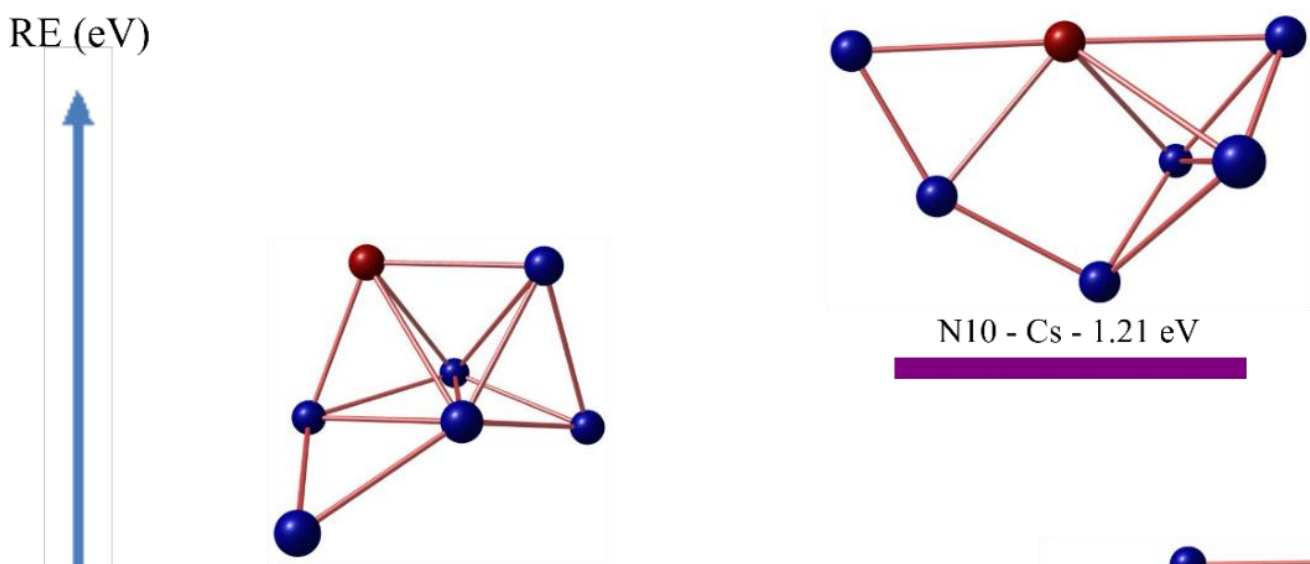

$\mathrm{N} 10-\mathrm{Cs}-1.21 \mathrm{eV}$

$\mathrm{N} 9-\mathrm{C}_{1}-0.78 \mathrm{eV}$
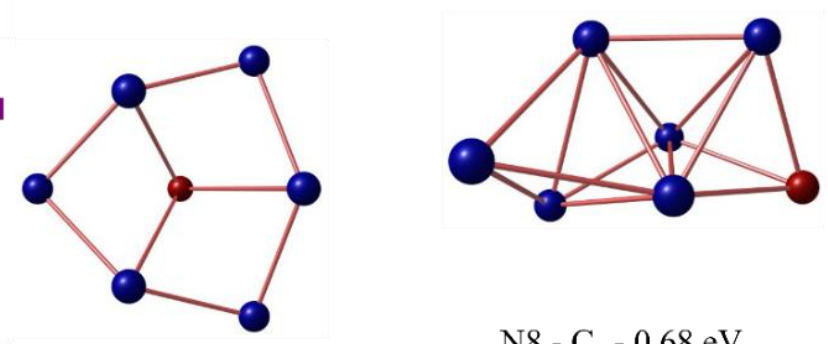

$\mathrm{N} 8-\mathrm{C}_{1}-0.68 \mathrm{eV}$
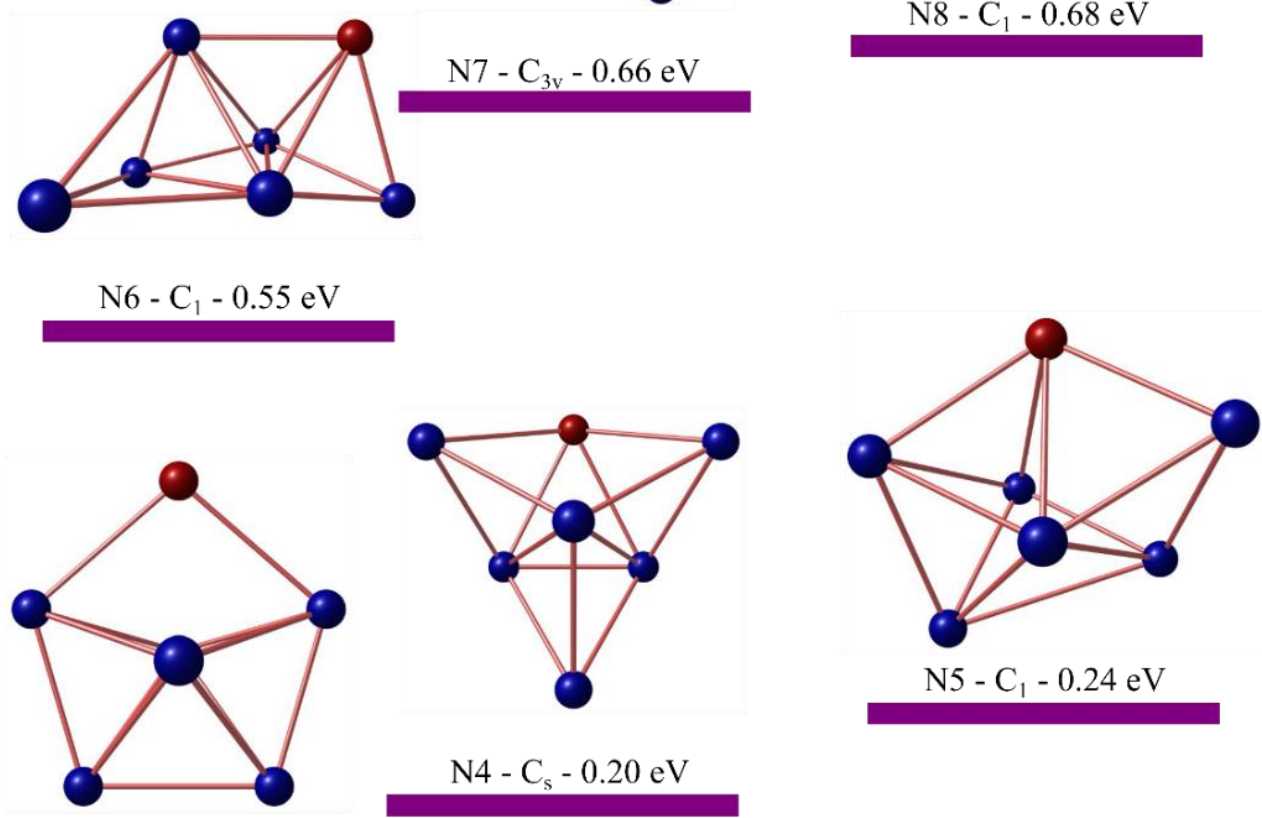

$\mathrm{N} 4-\mathrm{C}_{\mathrm{s}}-0.20 \mathrm{eV}$

$\mathrm{N} 3-\mathrm{C}_{2 \mathrm{v}}-0.16 \mathrm{eV}$
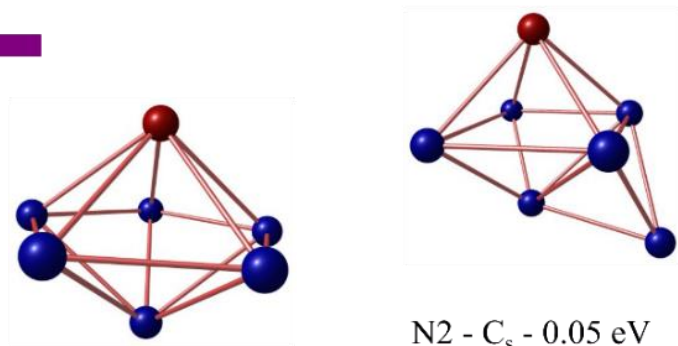

$\mathrm{N} 2-\mathrm{C}_{\mathrm{s}}-0.05 \mathrm{eV}$

$\mathrm{N} 1-\mathrm{C}_{\mathrm{s}}-0.00 \mathrm{eV}$

Figure 1. The geometrical, symmetry point group, relative energies of isomers of $\mathrm{ScGe}_{6}$ cluster 
Table 1. Symmetry point group, relative energies of isomers of $\mathrm{ScGe}_{6}$ cluster by PBE functional and DLPNO-

\begin{tabular}{cccc} 
& & \multicolumn{2}{c}{ CCSD(T) method } \\
\cline { 3 - 4 } Isomers & Symmetry & PBE & DLPNO-CCSD(T) \\
\cline { 3 - 4 } & & 0.02 & 0.00 \\
N1 & $\mathrm{C}_{\mathrm{s}}$ & 0.07 & 0.05 \\
N2 & $\mathrm{C}_{\mathrm{s}}$ & 0.00 & 0.16 \\
N4 & $\mathrm{C}_{\mathrm{s}}$ & 0.28 & 0.20 \\
N5 & $\mathrm{C}_{\mathrm{s}}$ & 0.23 & 0.24 \\
N6 & $\mathrm{C}_{1}$ & 0.48 & 0.55 \\
N7 & $\mathrm{C}_{1}$ & 0.49 & 0.66 \\
N8 & $\mathrm{C}_{3 \mathrm{v}}$ & 0.51 & 0.68 \\
N9 & $\mathrm{C}_{1}$ & 0.68 & 0.78 \\
$\mathrm{~N} 10$ & $\mathrm{C}_{1}$ & 1.08 & 1.21 \\
\hline
\end{tabular}

The geometrical structures, bond lengths of two isomers of $\mathrm{N} 1$ and $\mathrm{N} 2$ of $\mathrm{ScGe}_{6}$ cluster were displayed in Figure 2. Isomer N1 has a pentagonal bipyramid structure with a Sc atom at the vertex. Point group symmetry of $\mathrm{N} 1$ is $\mathrm{C}_{s}$ symmetry. The bond lengths of the $\mathrm{Sc}$ atom to the $\mathrm{Ge}$ atom on the base are from 2.749 Angstrom to 3.021 Angstrom. The bond lengths of $\mathrm{Ge}-\mathrm{Ge}$ in isomer N1 structure are from 2.513 Angstrom of Ge-Ge bond on the base to 2.859 Angstrom of bond from a Ge atom on the base to a Ge atom at the vertex. Isomer $\mathrm{N} 2$ has a face-capped tetragonal bipyramidal structure with Cs symmetry. The bond lengths of Sc-Ge are from 2.676 Angstrom to 2.687 Angstrom. The shortest and largest Ge-Ge average bond lengths are respectively 2.531 Angstrom and 2.776 Angstrom.

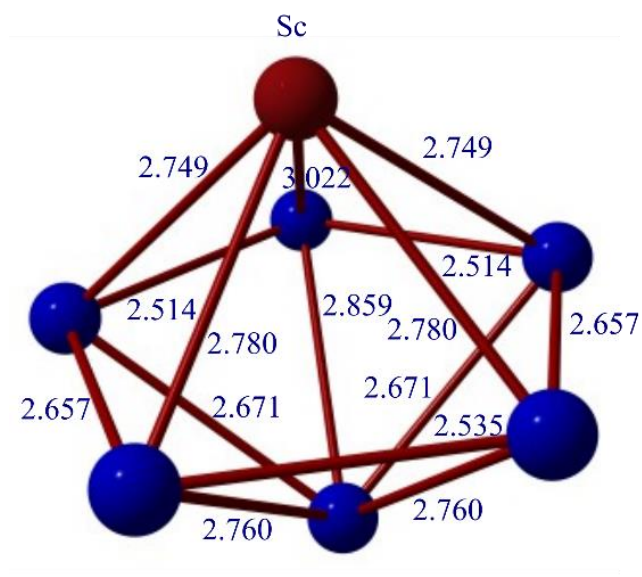

isomer N1

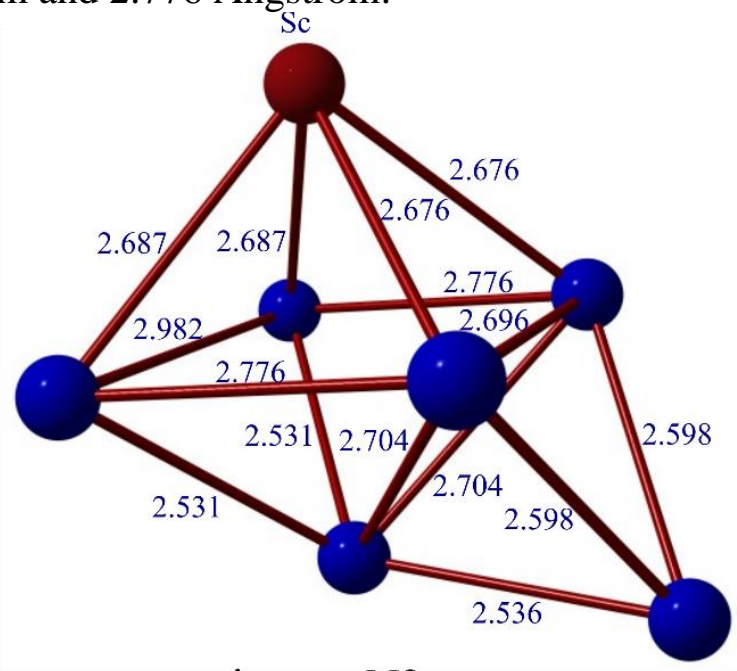

isomer N2

Figure 2. The bond lengths of two stable isomers of $\mathrm{ScGe}_{6}$ clusters

\subsection{Structure, relative stability of $\mathrm{ScGe}_{6}^{-}$clusters}

The geometrical structures, symmetry point group, relative energies of 8 isomers of anionic cluster $\mathrm{ScGe}_{6}{ }^{-}$ are presented in Figure 3 and Table 2. The order stability of isomers of $\mathrm{ScGe}_{6}{ }^{-}$cluster is good fitness between two methods of PBE functional and DLPNO-CCSD(T) calculations. Isomer A1 is the most stable isomer of the $\mathrm{ScGe}_{6}{ }^{-}$cluster. This result is the same as the previous report [18]. The other isomers are less stable $0.77 \mathrm{eV}(\mathrm{PBE})$ and $0.86 \mathrm{eV}(\mathrm{DLPNO}-\mathrm{CCSD}(\mathrm{T}))$ than $\mathrm{A} 1$ isomer. Two isomers of A2 and A3 have equivalent stability with the near degeneration in energy of the $0.77 \mathrm{eV}$ and $0.79 \mathrm{eV}$ at PBE calculations and $0.86 \mathrm{eV}$ and $0.88 \mathrm{eV}$ at DLPNO-CCSD(T) calculations. 
$\mathrm{RE}(\mathrm{eV})$

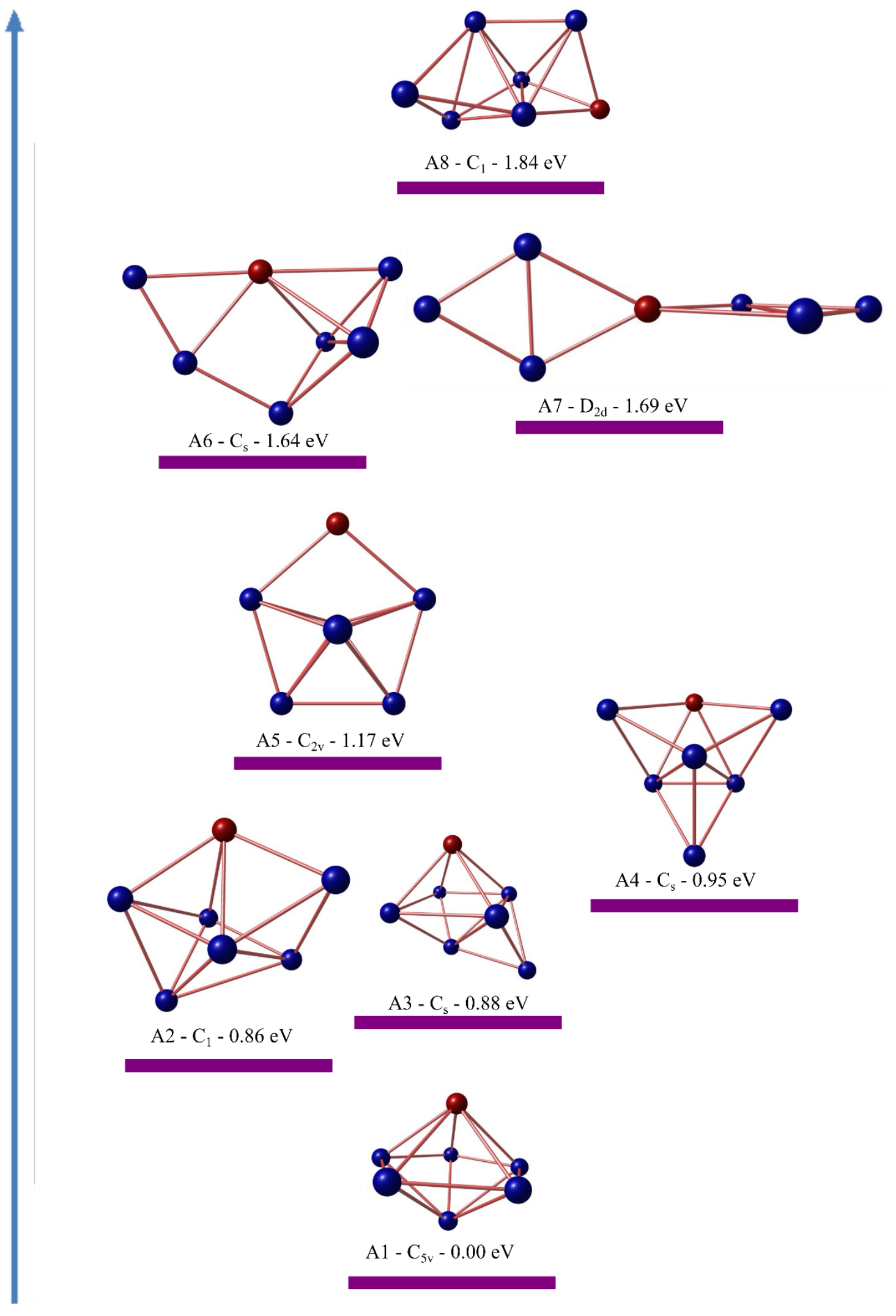

Figure 3. The geometrical structure, symmetry point group, relative energies of isomers of anionic cluster $\mathrm{ScGe}_{6}$ 
Table 2. Symmetry point group, relative energies of isomers of $\mathrm{ScGe}_{6}{ }^{-}$cluster by PBE functional and DLPNO-

\begin{tabular}{cccc} 
& \multicolumn{3}{c}{ CCSD(T) method } \\
\cline { 3 - 4 } Isomer & Symmetry & \multicolumn{2}{c}{ Relative energies (eV) } \\
\cline { 3 - 4 } & & 0.00 & DLPNO-CCSD(T) \\
A1 & $\mathrm{C}_{5 \mathrm{v}}$ & 0.77 & 0.00 \\
$\mathrm{~A} 2$ & $\mathrm{C}_{1}$ & 0.79 & 0.86 \\
$\mathrm{~A} 3$ & $\mathrm{C}_{\mathrm{s}}$ & 0.89 & 0.88 \\
$\mathrm{~A} 4$ & $\mathrm{C}_{\mathrm{s}}$ & 1.32 & 0.95 \\
$\mathrm{~A} 5$ & $\mathrm{C}_{2 \mathrm{v}}$ & 1.45 & 1.17 \\
$\mathrm{~A} 6$ & $\mathrm{C}_{\mathrm{s}}$ & 1.56 & 1.64 \\
$\mathrm{~A} 7$ & $\mathrm{D}_{2 \mathrm{~d}}$ & 1.54 & 1.69 \\
$\mathrm{~A} 8$ & $\mathrm{C}_{1}$ & & 1.84 \\
\hline
\end{tabular}

The relative of A4, A5, A6, A7, A8 isomers are higher than the A1 isomer by $0.95,1.17,1.64,1.69,1.84$ $\mathrm{eV}$ respectively at DLPNO-CCSD $(\mathrm{T})$. These obtained values of relative energies by PBE functional are from $0.89 \mathrm{eV}$ to $1.54 \mathrm{eV}$. In the previous report, three structures of the $\mathrm{ScGe}_{6}{ }^{-}$cluster are respectively A, $\mathrm{B}$, and $\mathrm{C}$ structures [18]. In this report, they are A1, A5 and A7, respectively. Besides, A2, A3, A4 isomers are more stable than $\mathrm{A} 5$ isomer. Two isomers of $\mathrm{A} 6$ and $\mathrm{A} 8$ are equivalent to $\mathrm{A} 7$ isomer.

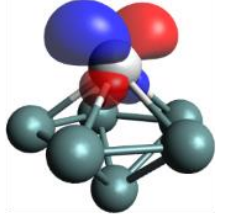

$67 \mathrm{a}^{\prime}(1.16 \mathrm{eV})$
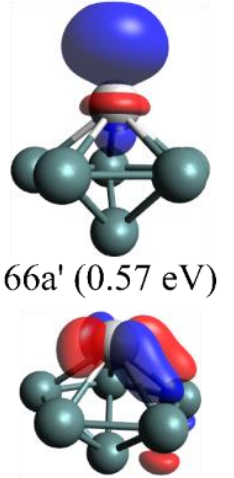

$65 \mathrm{a}^{\prime}(0: 23 \mathrm{eV})$

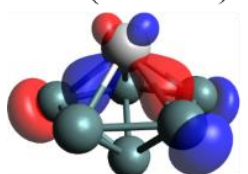

$64 a^{\prime}(-0.87 \mathrm{eV})$

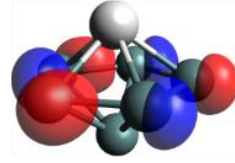

$63 a^{\prime}(-1.24 \mathrm{eV})$

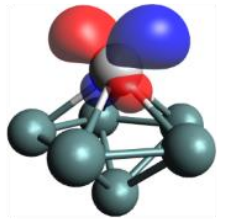

$45 \mathrm{a}^{\prime \prime}(1.16 \mathrm{eV})$

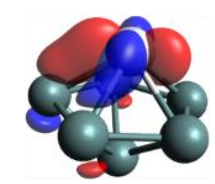

$44 a^{\prime \prime}(0.23 \mathrm{eV})$

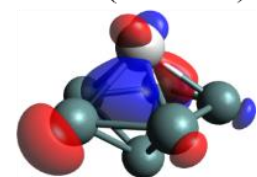

$43 \mathrm{a} "(-0.87 \mathrm{eV})$

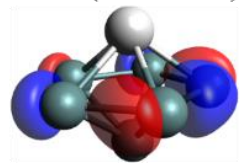

$42 \mathrm{a} "(-1.24 \mathrm{eV})$

Figure 4. The molecular orbitals of ${ }^{1} \mathrm{~A}$ ' state of $\mathrm{A} 1$ isomer of $\mathrm{ScGe}_{6}{ }^{-}$cluster obtained by PBE functional, def2TZVPP basis set (with Sc atom at above of pyramid)

The most stable A1 isomer of $\mathrm{ScGe}_{6}{ }^{-}$cluster has a $\mathrm{C}_{5 \mathrm{v}}$ symmetry point group. Because $\mathrm{C}_{5 \mathrm{v}}$ is not an Abelian point group, so the calculations were reduced to the $\mathrm{C}_{\mathrm{s}}$ point group. The figure and energy values of 
molecular orbitals of ${ }^{1} \mathrm{~A}$ ' state of $\mathrm{A} 1$ isomer of $\mathrm{ScGe}_{6}{ }^{-}$cluster as in Figure 4. The electronic structure of ${ }^{1} \mathrm{~A}^{1}$ state of A1 isomer of $\mathrm{ScGe}_{6}{ }^{-}$cluster is $63 \mathrm{a}^{\prime 2} 42 \mathrm{a}^{\prime 2} 64 \mathrm{a}^{2} 43 \mathrm{a}^{\prime 2} 44 \mathrm{a}^{\prime \prime} 65 \mathrm{a}^{\prime 0} 66 \mathrm{a}^{\prime 0}$. The bond length of Sc-Ge bonds and Ge-Ge bonds which are optimized at PBE functional and def2-TZVPP basis set is displayed in Figure 5a. The bond lengths of Sc to Ge in the base, Ge-Ge in the base, Ge in the base to Ge at the bipyramid vertex are respectively 2.779, 2.595, 2.713 Angstrom. By B3LYP functional, these bond lengths are respectively 2.79, 2.6, 2.75 Angstrom [18]. The bond lengths of Sc to Ge in the base, Ge-Ge in the base, $\mathrm{Ge}$ in the base to Ge at the bipyramid vertex are respectively 2.779, 2.595, 2.713 Angstrom. By B3LYP functional, these bond lengths are respectively 2.79, 2.6, 2.75 Angstrom [18].

\subsection{The $\mathrm{CO}$ adsorption of $\mathrm{ScGe}_{6}{ }^{-}$cluster}

The structure of the CO molecule was optimized at PBE functional, def2-TZVPP basic set as in Figure 5b. The bond length harmonic vibrational frequency of C-O is 1.136 Angstrom. This result is the same as the result of Feng, R., et al. [27]. The $\mathrm{CO}$ adsorption processes were performed by optimizing the random structure of the $\mathrm{CO}$ molecule on the surface of $\mathrm{ScGe}_{6}{ }^{-}$cluster does not constrain symmetry. Then, the symmetry calculations were done to determine the point group symmetry of geometrical structures. The frequency values were also calculated to confirm the obtained structure at the minimum position on the potential surface. Three models and relative energies of $\mathrm{CO}$ adsorption on the $\mathrm{A} 1$ isomer of $\mathrm{ScGe}_{6}{ }^{-}$cluster were displayed in Figure 5c and Table 3.
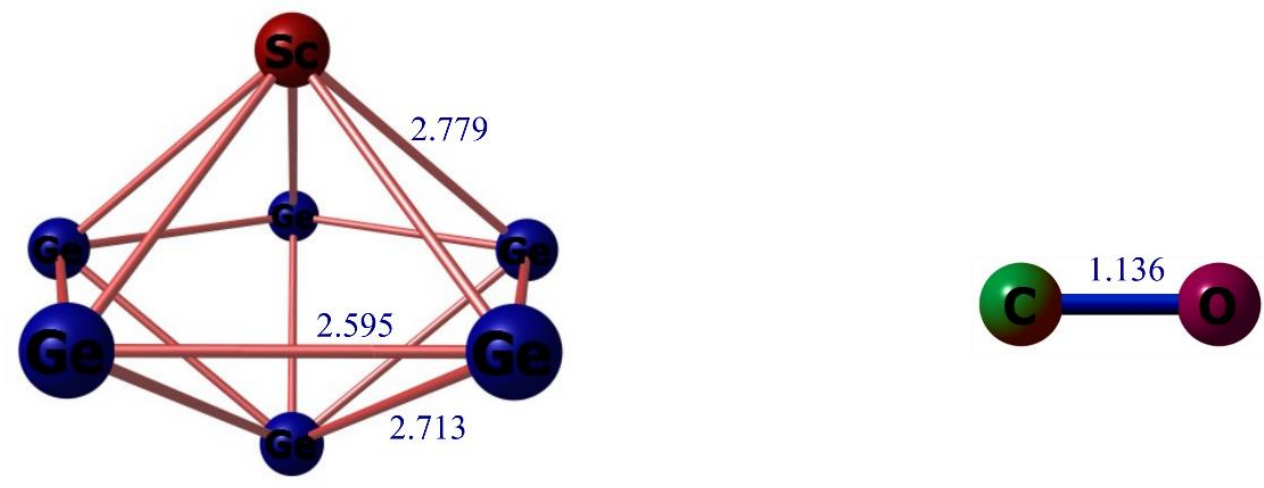

a) $\mathrm{A} 1$ isomer of $\mathrm{ScGe}_{6}{ }^{-}$cluster

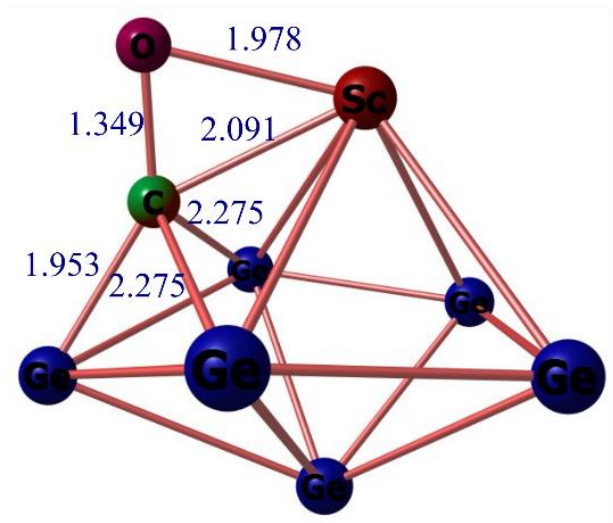

$\mathrm{A}-\mathrm{C}_{s}-0.00 \mathrm{eV}$

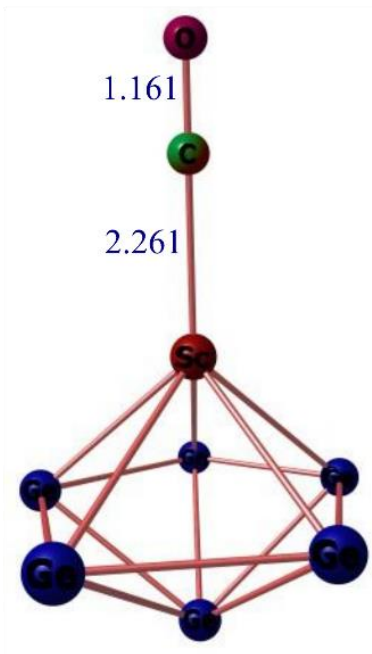

B $-\mathrm{C}_{s}-0.19 \mathrm{eV}$ b ) $\mathrm{CO}$

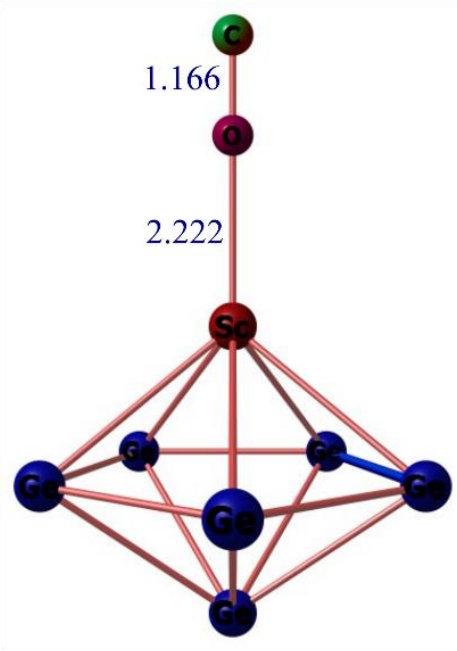

C $-\mathrm{C}_{s}-0.72 \mathrm{eV}$

c) $\mathrm{CO}$ adsorption on $\mathrm{A} 1$ isomer of $\mathrm{ScGe}_{6}{ }^{-}$cluster

Figure 5. The structures of $\mathrm{A} 1$ isomer of $\mathrm{ScGe}_{6}{ }^{-}$cluster a), $\mathrm{CO}$ molecule b) $\mathrm{CO}$ adsorption by $\mathrm{ScGe}_{6}{ }^{-}$cluster obtained by PBE functional, def2-TZVPP basis set 
The A structure which is the most stable structure has the $\mathrm{C}_{\mathrm{s}}$ symmetry point group. In this structure, the $\mathrm{CO}$ molecule was adsorbed at beside bond Sc-Ge. The $\mathrm{B}$ structure and $\mathrm{C}$ structure are also both at $\mathrm{C}_{s}$ point group symmetry with $\mathrm{CO}$ molecule at pyramid containing Sc. The B and $\mathrm{C}$ structures are less stable 0.19 $\mathrm{eV}$ and $0.72 \mathrm{eV}$, respectively. The model of Sc-CO is stable than the Sc-OC model as the relative energies at PBE functional, def2-TZVPP basis set. The $\mathrm{Sc}-\mathrm{CO}$ model is the same as the CO adsorption on $\mathrm{Sc}_{n}(n=2-$ 13) [17]. The A structure which is the most stable structure can be explained by the ability in creating many interactions between $\mathrm{CO}$ molecule with the $\mathrm{Sc}, \mathrm{Ge}$ atoms on $\mathrm{ScGe}_{6}{ }^{-}$cluster. In A structure, $\mathrm{C}$ of $\mathrm{CO}$ interacts with $\mathrm{Sc}$ and $3 \mathrm{Ge}$ atoms; $\mathrm{O}$ of $\mathrm{CO}$ interacts with Sc. Because of multi-interactions, the $\mathrm{C}-\mathrm{O}$ bond length on A structure is 1.35 Angstrom, which is longer than the $\mathrm{C}-\mathrm{O}$ bond length in the $\mathrm{CO}$ molecule. The adsorption energy of $\mathrm{A}$ is $1.08 \mathrm{eV}$. In $\mathrm{B}$ or $\mathrm{C}$ structure, only one interacts between $\mathrm{CO}$ molecule and $\mathrm{ScGe}_{6}{ }^{-}$cluster. The $\mathrm{C}-\mathrm{O}$ bond length in $\mathrm{B}$ structure, $\mathrm{C}$ structure, and $\mathrm{CO}$ molecule is equivalent.

Table 3. Relative energies, C-O bond lengths, energies of adsorption processes by anion cluster

\begin{tabular}{|c|c|c|c|}
\hline Structure & Relative energies (eV) & C-O bond length (Angstrom) & Adsorption energy (eV) \\
\hline CO molecule & & 1.136 & \\
\hline A & 0.00 & 1.349 & 1.08 \\
\hline B & 0.19 & 1.161 & 0.89 \\
\hline C & 0.72 & 1.171 & 0.36 \\
\hline
\end{tabular}

\section{CONCLUSION}

The structures of the $\mathrm{ScGe}_{6}$ cluster was investigated by GA-DFT calculations. Their relative energies of stable isomers of $\mathrm{ScGe}_{6}$ cluster and $\mathrm{ScGe}_{6}{ }^{-}$cluster were reported at PBE/def2-TZVPP level and DLPNO$\mathrm{CCSD}(\mathrm{T}) /$ aug-cc-pVTZ level. The most stable structures of $\mathrm{ScGe}_{6}$ and $\mathrm{ScGe}_{6}{ }^{-}$are the pentagonal bipyramid with the Sc atom at the vertex. The symmetry point group of the most stable neutral cluster and anionic cluster are respectively $\mathrm{C}_{s}$ and $\mathrm{C}_{5 v}$. Many isomers are near degenerate in energy. The stability of $\mathrm{N} 2$ is less stable than $\mathrm{N} 1$ by $0.05 \mathrm{eV}$. The isomer $\mathrm{A} 1$ of the $\mathrm{ScGe}_{6}{ }^{-}$cluster can adsorb $\mathrm{CO}$ molecule as well. The most stable structure has $\mathrm{CO}$ along with the Sc-Ge bond. In two adsorption models at the Sc atom along the main axis, the Sc-CO adsorption model is more favorable than the Sc-OC model in adsorption energy.

\section{REFERENCES}

1. S. Biswas, S. Barth, and J.D. Holmes, Nano Res., vol. 10, pp. 1-14, 2017

2. B.F.P. McVey, S. Prabakar, J.J. Gooding, and R.D. Tilley, ChemPlusChem, vol. 82, pp. 60-73, 2017

3. P.R. Abel, A.M. Chockla, Y.-M. Lin, V.C. Holmberg, J.T. Harris, B.A. Korgel, A. Heller, and C.B.

Mullins, J. Am. Chem. Soc., vol. 7, pp. 2249-2257, 2013

4. D. Carolan, Prog. Mater Sci., vol. 90, pp. 128-158, 2017

5. E. Janssens, S. Neukermans, X. Wang, N. Veldeman, R. Silverans, and P. Lievens, Eur. Phys. J. D, vol. 34, pp. 23-27, 2005

6. D. Bandyopadhyay, and P. Sen, J. Phys. Chem. A, vol. 114, pp. 1835-1842, 2010

7. L. Giuseppe, M. Salvatore, M. Arcangelo, and D. Michel, J. Chem. Soc., Faraday Trans., vol. 89, pp. 7, 1993

8. G. Pacchioni, and J. Koutecký, J. Chem. Phys., vol. 84, pp. 3301-3310, 1986

9. J. Wang, and J.-G. Han, J. Chem. Phys., vol. 123, pp. 244303, 2005

10. J. Wang, G. Wang, and J. Zhao, Phys. Rev. B, vol. 64, pp. 205411, 2001

11. A. Ugrinov, and S.C. Sevov, J. Am. Chem. Soc., vol. 124, pp. 10990-10991, 2002

12. K.A. Gingerich, M. Sai Baba, R.W. Schmude Jr, and J.E. Kingcade Jr, Chem. Phys., vol. 262, pp. 65-74, 2000 
13. A.A. Shvartsburg, B. Liu, Z.-Y. Lu, C.-Z. Wang, M.F. Jarrold, and K.-M. Ho, Phys. Rev. Lett., vol. 83, pp. 2167-2170, 1999

14. I. Pápai, and M. Castro, Chem. Phys. Lett., vol. 267, pp. 551-556, 1997

15. S. Sajjad, T. Mahmood, R. Ludwig, and K. Ayub, Solid State Sci., vol. 86, pp. 60-68, 2018

16. S. Sajjad, M.A. Hashmi, T. Mahmood, and K. Ayub, Comput. Theor. Chem., vol. 1163, pp. 2019

17. Y. Wang, G. Wu, J. Du, M. Yang, and J. Wang, J. Phys. Chem. A, vol. 116, pp. 93-7, 2012

18. N. Borshch, N. Pereslavtseva, and S. Kurganskii, Russ. J. Phys. Chem. B, vol. 9, pp. 9-18, 2015

19. J. Atobe, K. Koyasu, S. Furuse, and A. Nakajima, Phys. Chem. Chem. Phys., vol. 14, pp. 9403-9410, 2012

20. X.-J. Deng, X.-Y. Kong, H.-G. Xu, X.-L. Xu, G. Feng, and W.-J. Zheng, J. Phys. Chem. C, vol. 119, pp. 11048-11055, 2015

21. C. Siouani, S. Mahtout, S. Safer, and F. Rabilloud, J. Phys. Chem. A, vol. 121, pp. 3540-3554, 2017

22. X.-J. Deng, X. Kong, X.-L. Xu, and W.-J. Zheng, RSC Adv., vol. 4, pp. 25963-25968, 2014

23. X.-J. Deng, X.-Y. Kong, X.-L. Xu, H.-G. Xu, and W.-J. Zheng, ChemPhysChem, vol. 15, pp. 3987-3993, 2014

24. X.-J. Deng, X.-Y. Kong, X. Liang, B. Yang, H.-G. Xu, X.-L. Xu, G. Feng, and W.-J. Zheng, J. Chem. Phys., vol. 147, pp. 234310, 2017

25. S. Zhou, X. Yang, Y. Shen, R.B. King, and J. Zhao, J. Alloys Compd., vol. 806, pp. 698-704, 2019

26. V. Nagarajan, and R. Chandiramouli, J. Mol. Liq., vol. 234, pp. 355-363, 2017

27. R. Feng, E.D. Glendening, and K.A. Peterson, Inorg Chem, vol. 59, pp. 4753-4763, 2020

28. P. Jennings, and R. Johnston, Comput. Theor. Chem., vol. 1021, pp. 91-100, 2013

29. Y. Minenkov, E. Chermak, and L. Cavallo, J. Chem. Theory. Comput., vol. 11, pp. 4664-76, 2015

30. C. Riplinger, and F. Neese, J. Chem. Phys., vol. 138, pp. 034106, 2013

31. Y. Guo, C. Riplinger, D.G. Liakos, U. Becker, M. Saitow, and F. Neese, J. Chem. Phys., vol. 152, pp. 024116,2020

32. H.A. Hussein, and R.L. Johnston, The DFT-genetic algorithm approach for global optimization of subnanometer bimetallic clusters, in Frontiers of Nanoscience. 2019, Elsevier. p. 145-169.

33. A.R. Oganov, and C.W. Glass, J. Chem. Phys., vol. 124, pp. 244704, 2006

34. A.O. Lyakhov, A.R. Oganov, H.T. Stokes, and Q. Zhu, Comput. Phys. Commun., vol. 184, pp. 1172-1182, 2013

35. A.R. Oganov, A.O. Lyakhov, and M. Valle, Acc. Chem. Res., vol. 44, pp. 227-237, 2011

36. P. Giannozzi, S. Baroni, N. Bonini, M. Calandra, R. Car, C. Cavazzoni, D. Ceresoli, G.L. Chiarotti, M. Cococcioni, I. Dabo, A. Dal Corso, S. de Gironcoli, S. Fabris, G. Fratesi, R. Gebauer, U. Gerstmann, C. Gougoussis, A. Kokalj, M. Lazzeri, L. Martin-Samos, N. Marzari, F. Mauri, R. Mazzarello, S. Paolini, A. Pasquarello, L. Paulatto, C. Sbraccia, S. Scandolo, G. Sclauzero, A.P. Seitsonen, A. Smogunov, P. Umari, and R.M. Wentzcovitch, J. Condens. Matter Phys., vol. 21, pp. 395502, 2009

37. J.P. Perdew, K. Burke, and M. Ernzerhof, Phys. Rev. Lett., vol. 77, pp. 3865-3868, 1996

38. N.B. Balabanov, and K.A. Peterson, J. Chem. Phys., vol. 123, pp. 064107, 2005

39. N.B. Balabanov, and K.A. Peterson, J. Chem. Phys., vol. 125, pp. 074110, 2006

40. F. Neese, Wiley Interdiscip. Rev. Comput. Mol. Sci, vol. 2, pp. 73-78, 2012

41. T. Chachiyo, and H. Chachiyo, Comput. Theor. Chem., vol. 1172, pp. 112669, 2020 


\section{NGHIÊN CƯU CÁC CÂU TRÚC BỄN CỦA CÁC CLUSTER ScGe 6 BÀ̀NG PHƯƠNG PHÁP GA-DFT VÀ SỰ HẤP PHỤ CO TRÊN CLUSTER ScGe- ${ }^{-}$}

Tóm tắt. Cấu trúc của cluster $\mathrm{ScGe}_{6}$ và $\mathrm{ScGe}_{6}{ }^{-}$được nghiên cứu cứu bằng giải thuật di truyền kết hợp các phép tính hóa học lượng tử (GA-DFT và DLPNO-CCSD $(T)$ ). Kết quả cho thấy hai đồng phân bền nhất của cluster $\mathrm{ScGe}_{6}$ có dạng lượng tháp ngũ giác với nguyên tử $\mathrm{Sc}$ ở đỉnh và cluster dạng lưỡng tháp tứ giác với Sc ở đỉnh với một nguyên tử Ge che ở mặt. Cấu trúc của hai đồng phân bền nhất của cluster trung hòa $\mathrm{ScGe}_{6}$ có đối xứng $\mathrm{C}_{s}$. Cluster $\mathrm{ScGe}_{6}{ }^{-}$có cấu trúc lưỡng tháp ngũ giác với nguyên tử $\mathrm{Sc}$ ở đỉnh thuộc nhóm điểm đối xứng $\mathrm{C}_{5 v}$. Các cấu trúc hấp phụ $\mathrm{CO}$ của cluster $\mathrm{ScGe}_{6}{ }^{-}$được nghiên cứu. Sự hấp phụ $\mathrm{CO}$ trên đồng phân bền nhất của cluster $\mathrm{ScGe}_{6}{ }^{-}$được thực hiện với phiếm hàm PBE. Cấu trúc hấp phụ bền nhất có $\mathrm{CO}$ ở dọc theo cạnh liên kết Sc-Ge. Trong hai cấu trúc hấp phụ dọc theo trục chính tại nguyên tử Sc, kiểu hấp phụ $\mathrm{Sc}-\mathrm{CO}$ bền hơn kiểu hấp phụ Sc-OC.

Từ khóa: cluster $\mathrm{ScGe}_{6}{ }^{0 /-}$, giải thuật di truyền, DFT, DLPNO-CCSD(T), sự hấp phụ CO

Ngày nhận bài:14/08/2020

Ngày chấp nhận đăng:08/01/2021 